\title{
One Approach to Eddy Current Testing of Carburized
}

\section{Parts}

\author{
J. Ivanov \\ M+S Hydraulic PLC, Kazanlak 6100, Bulgaria
}

\begin{abstract}
Through DOE (design of experiment), ET (eddy current testing) is included and proven as a quality indicator of carburizing, quenching and tempering of hydraulic motor parts. A method is suggested for calibrating NDT (non-destructive testing) by means of combined representation of regression models in the field of the technological factors of heat treatment and contour control charts. A method is presented here for choosing the working frequency for ET. It is also suggested that experimental design be considered a basic building element in the methodology of carburized parts ET. This article also presents a methodology for conducting eddy current testing in industrial settings.
\end{abstract}

Key words: ET, carburized parts, DOE.

\section{Introduction}

The problems with the control of carburized, quenched and low-temperature tempered parts in the conditions of hydraulic motor mass production are connected with a number of factors, among which are shape, size, the technological sequence of different treatments, the function of parts, etc.

In its essence, carburizing changes the chemical composition of surfaces. The result is diffusion layers of varying depth, usually between 0.5 and $1.2 \mathrm{~mm}$, with a higher content of carbon. After quenching and low-temperature tempering, a big group of the parts acquire their final performance levels. One such example is power take-off drive shafts. Their additives are of around $0.2 \mathrm{~mm}$. The processing interferes with the wholeness and structure of the cementation layer, removing different sub-layers. This effect can work two ways. It is possible to remove a useful part of the diffusion layer which is essential for the performance. Alternatively, a defective sub-layer may be removed or revealed. This is connected with a change in the

Corresponding author: Jan Ivanov, M.Sc., Ph.D. candidate, research fields: carburized parts control, low temperature tempering, DOE, eddy currents. tension in certain zones in the part. What is more, there are always transition zones in the parts between areas with final processing and areas without such processing.

A third group of parts, for example hydraulic motor output shafts, contain inside splines, which do not undergo finishing mechanical processing, and external areas, which have precise/finished/dimensions after grinding.

It is easily established that the processes of friction and wear in high contact tension zones occur mostly between areas which do not undergo grinding or other processing, such as "rotor internal splines-PTO shaft" and "PTO shaft-output shaft internal splines" friction pairs.

It is in such cases that the control of carburizing, quenching and tempering becomes especially important.

\section{Carburizing Control: Eddy Current Method}

Like any other technological stage, thermochemical treatment is subjected to the joint influence of the preset rates of technological factors and random interference [1]. The parts subjected to these 
influences acquire a complex of properties, called quality indicators. The maintenance of constant levels for the technological factors does not always ensure uniformity in the quality indicators, and this is mainly due to random interference [1]. The intentional change in the technological factor levels, the subsequent result are incorporated in the motors with all changes in the size and shape caused by the thermochemical treatment. The quenched diffusion layer is preserved in its entirety, with all its peculiarities, some of which are proven flaws.

Another group of carburized and quenched parts undergo additional technological operations before assembly, such as grinding and lapping. Today's finishing processing requires the availability of grinding, and the continuous monitoring of a technological object represent the only possibility of getting to know it and optimizing it [1]. Included in the designed experiment methodology, the stages of optimization require the right formulation and the right approach to solving specific tasks.

It is widely known that the technical control of carburized parts encompasses the results for a number of quality indicators: Rockwell hardness, Vickers hardness, carburizing depth and effective depth, phase composition of the quenched layer and the core $[2,3]$. In large lot production settings, the number of parts whose indicators are controlled constitutes a small percentage. It is in such cases that the introduction of statistical methods seems unreliable for this and other reasons, too, which determine deviations in the results. A changed formulation of the technical control task is only possible if a quick and effective testing method is used, which, of course, is also non-destructive, too. With its essence and possibilities, the eddy current testing method looks the most feasible one in industrial settings. This, however, will require that the eddy current testing results be considered a quality indicator, along with all the others mentioned above [4]. The group of quality indicators can be extended with the results of carburized parts performance testing, i.e. durability and fatigue strength [5]. This so-formed set allows for prioritizing the separate quality indicators. Such a classification can give the highest priority to fatigue strength as a performance indicator, while at the same time assigning a descriptive and complementary function to all the other indicators, such as hardness, structure and electromagnetic properties. Unlike all other quality indicators, eddy current testing assessment can encompass as much as $100 \%$ of the parts intended for control, and its quick and easy implementation for different zones of the tested specimen, can provide useful information in favor of conducting destructive testing. Eddy current testing is widely used for non-destructive testing of flaws on the surface and just under the surface [6]. At the same time, it is reliable in registering changes in the inside tension, in the structure and the mechanical properties, which proves their relationship with the electro-magnetic properties of materials $[2,7,8]$. Eddy currents are affected by the relative magnetic permeability $\mu_{r}$ and the electrical conductivity $-\sigma$, which are different for the different steels and their states [2, 7-9]. The value and the maximal value of $\mu_{r}$ depend on the magnetic field strength, the difference in the chemical composition and the heat treatment which has been conducted [7]. Eddy current testing is a comparative and integral method [2, 8]. It does not provide accurate values of hardness and quench depths. It is sensitive to the slightest changes in the structure and properties of materials $[2,7]$. The formula of penetration depth of eddy currents is well known as "Skin Effect" [2, 6, 9]. Variations in the frequency of the field current from $10 \mathrm{~Hz}$ to $100 \mathrm{kHz}$ can result in eddy current penetration from 0.01 to $100 \mathrm{~mm}$ [9]. Registering, digitalizing [7], and regarding the evaluation from the eddy current testing as a function of the technological factors, as well as its simultaneous analysis with the rest of the quality indicators, represent an important possibility to calibrate and implement the method in industrial settings. 
The effect of technological factors can be estimated by means of regression analysis. The resulting regression models for each quality indicator, such as [1]

$$
\begin{gathered}
\hat{y}=b_{0+} \sum_{i=1}^{m} b_{i} x_{i}++\sum_{i=1}^{m-1} \sum_{j=i+1}^{m} b_{i j} x_{i} x_{j} \\
+\sum_{x=1}^{m} b_{i i} x_{i}^{2}+\cdots
\end{gathered}
$$

and their adequacy estimates [1]: $R, F, R_{a d j-s q}, R_{-s q(\text { pred })}, p$, can be used as criteria when it comes to the sensitivity of each one of the quality indicators to the changes occurring at the starting point of gas carburizing.

\section{Object of Research}

Carburizing is carried out for $18 \mathrm{CrNiMo} 7-6,1.6587$, DIN EN 10084 steel parts [11] according to DOE №1. The parts are tested by means of eddy currents at one working frequency. The experiment takes into consideration the effect of technological factors on the full range of quality indicators.

Carburizing is carried out for 18CrNiMo7-6, 1.6587 steel parts according to DOE №2. The parts are tested at different working frequencies of the eddy current instrument.

\section{Objectives of Research}

The research aims to present stages in the formation of a working methodology for carburized parts testing. To achieve this aim, it is necessary to do the following:

(1) Introduce a new quality indicator, namely, the results of the eddy current test.

(2) Prove the sensitivity of ET results/eddy current testing results/to the changes in technological factors.

(3) Jointly consider all quality indicators with the purpose of calibrating the eddy current instrument.

(4) Suggest a method of selecting working frequencies, with the purpose of optimizing the non-destructive testing.

\section{Methodology of Research}

The methodology of research involves testing parts which have been carburized, quenched and tempered according to two designed experiments. The levels of the technological factors of experiment №1 are given in Table 1 [4].

Technical problems prevented the maintenance of the planned values for tempering temperatures $T_{T}$. In the real interval between $\min T_{T}$ and $\max T_{T}$, the obtained value for the coded basic level of the factor $x_{2}$ is -0.23 .

\begin{tabular}{|c|c|c|c|c|c|c|c|}
\hline & $x_{1}$ & $x_{2}$ & $x_{1}$ & \multicolumn{2}{|l|}{$x_{2}$} & & \\
\hline 1 & -1 & 0 & $2 \mathrm{~h}$ & \multicolumn{2}{|l|}{$200^{\circ} \mathrm{C}$} & & \\
\hline 2 & 0 & 0 & $3 \mathrm{~h}$ & \multicolumn{2}{|l|}{$200^{\circ} \mathrm{C}$} & & \\
\hline 3 & 1 & 1 & $4 \mathrm{~h}$ & \multicolumn{2}{|l|}{$250^{\circ} \mathrm{C}$} & & \\
\hline 4 & -1 & 1 & $2 \mathrm{~h}$ & \multicolumn{2}{|l|}{$250^{\circ} \mathrm{C}$} & & \\
\hline 5 & 1 & 0 & $4 \mathrm{~h}$ & \multicolumn{2}{|l|}{$200^{\circ} \mathrm{C}$} & & \\
\hline 6 & 0 & -1 & $3 \mathrm{~h}$ & \multicolumn{2}{|l|}{$150^{\circ} \mathrm{C}$} & & \\
\hline 7 & 0 & 1 & $3 \mathrm{~h}$ & \multicolumn{2}{|l|}{$250^{\circ} \mathrm{C}$} & & \\
\hline 8 & 1 & -1 & $4 \mathrm{~h}$ & \multicolumn{2}{|l|}{$150^{\circ} \mathrm{C}$} & & \\
\hline \multirow[t]{2}{*}{9} & -1 & -1 & $2 \mathrm{~h}$ & $150^{\circ} \mathrm{C}$ & & & \\
\hline & & & Carburizing times & \multicolumn{2}{|c|}{$\begin{array}{c}\text { Planned } \\
\text { temperatures of tempering }\end{array}$} & \multicolumn{2}{|c|}{$\begin{array}{c}\text { Measured } \\
\text { temperatures of tempering }\end{array}$} \\
\hline \multicolumn{2}{|c|}{ Basic level } & & $3 \mathrm{~h}$ & $200^{\circ} \mathrm{C}$ & “0” & $194.5^{\circ} \mathrm{C}$ & -0.23 \\
\hline \multicolumn{2}{|c|}{ Lower level } & & $2 \mathrm{~h}$ & $150^{\circ} \mathrm{C}$ & “-1" & $158^{\circ} \mathrm{C}$ & -1 \\
\hline \multicolumn{2}{|c|}{ Upper level } & & $4 \mathrm{~h}$ & $250^{\circ} \mathrm{C}$ & “1” & $250^{\circ} \mathrm{C}$ & 1 \\
\hline
\end{tabular}

Table 1 DOE №1/PTO shafts. 
The technological factors which feature in DOE №2 are quenching temperature $T_{Q}$ and tempering temperature $T_{T}$.

Vickers- HV30 [12], and Rockwell- HRC [13] hardness are measured, and also the effective depth of the carburized level-CHD/Eht[14]. A comparative metallographic method is used to determine the content of residual austenite $-\% A_{\text {rest }}$ [3]. The test results gained from the eddy current instrument are marked with $Z$ [15].

The data are processed in a regression analysis, and the models are tested for their adequacy [16]. Examples are given of simultaneous consideration of two or more quality indicators, through their regression models. Fatigue strength data from a test stand are used and presented as a performance quality indicator.

\section{Experimental Results}

\subsection{DOE №1 [4]}

Columns 1 and 2 of Table 2 present the technological factor levels: carburizing time $x_{1}$ and tempering temperature $x_{2}$ in coded units. Column 3 contains the times, or hours, before destruction during fatigue strength testing, $h$. Columns 4 and 5 show Vickers and Rockwell hardness data. Column 6 contains carburizing depth data - CHD / Eht. Column 7 presents the percentage of residual austenite $A_{\text {rest }}$, calculated by comparing with reference series.
Column 8 contains the digitalized estimates of the eddy current testing, $Z 41$.

Below are the obtained models:

Fatigue stress model, $Y(h)=f\left(x_{1} ; x_{2}\right)$ :

$y=18.009+0.599 \cdot x_{1}+1.108 \cdot x_{2}-$

$-2.918 \cdot x_{2}{ }^{2}+2.699 \cdot x_{1} \cdot x_{2}$

Vickers surface hardness model,

$Y(H V 30)=f\left(x_{1} ; x_{2}\right)$ :

$y=658.089-15.471 \cdot x_{1}-26.667 \cdot x_{2}-$

$-9.833 \cdot x_{1}{ }^{2}+37.8 \cdot x_{2}{ }^{2}+13.418 \cdot x_{1} \cdot x_{2}$

Rockwell surface hardness model, $Y(H R C)=f\left(x_{1} ; x_{2}\right)$ :

$y=59.684-0.783 \cdot x_{1}-1.667 \cdot x_{2}+$

$+0.616 \cdot x_{2}^{2}$

Carburizing effective depth model,

$Y(C H D / E h t)=f\left(x_{1} ; x_{2}\right)$ :

$y=0.83+0.203 \cdot x_{1}-0.094 \cdot x_{2}+$

$+0.073 \cdot x_{1}^{2}-0.054 \cdot x_{1} \cdot x_{2}$

Residual austenite quantity model,

$Y\left(A_{\text {rest }}\right)=f\left(x_{1} ; x_{2}\right)$ :

$y=8.374+10.0 \cdot x_{1}-5.266 \cdot x_{2}$

ECT instrument readings model, $Y(Z 41)=f\left(x_{1} ; x_{2}\right):$

$y=0.736-0.229 \cdot x_{2}+0.526 \cdot x_{2}{ }^{2}+$

$+0.088 \cdot x_{1} \cdot x_{2}$

The contours of the constant values of the obtained regression models are presented in Fig. 1, and the results of their adequacy test are in Table 3.

Table 2 Quality indicator results -DOE № 1.

\begin{tabular}{llllllll}
\hline$x_{1}$ & $x_{2}$ & $h[\mathrm{~h}]$ & $H V 30$ & $H R C$ & $\begin{array}{c}\text { CHD/Eht, } \\
{[\mathrm{mm}]}\end{array}$ & Arest $[\%]$ & $Z 41$ \\
\hline 1 & 2 & 3 & 4 & 5 & 6 & 7 & 8 \\
1 & -1 & 16.4 & 742 & 62.8 & 0.72 & 0 & 1.55 \\
-1 & -0.23 & 17 & 668 & 61 & 0.72 & 0 & 0.85 \\
-1 & 1 & 12.9 & 668 & 58.8 & 0.67 & 0 & 0.95 \\
0 & -1 & 14.3 & 728 & 62.3 & 0.96 & 17 & 1.525 \\
0 & -0.23 & 17.3 & 670 & 60 & 0.84 & 2 & 0.8 \\
0 & 1 & 16.8 & 660 & 59.3 & 0.71 & 0 & 1 \\
1 & -1 & 11.25 & 678 & 60.8 & 1.22 & 25 & 1.4 \\
1 & -0.23 & 18.5 & 641 & 59.3 & 1.17 & 25 & 0.8 \\
1 & 1 & 18.9 & 660 & 57.8 & 0.96 & 10 & 1.15 \\
\hline
\end{tabular}




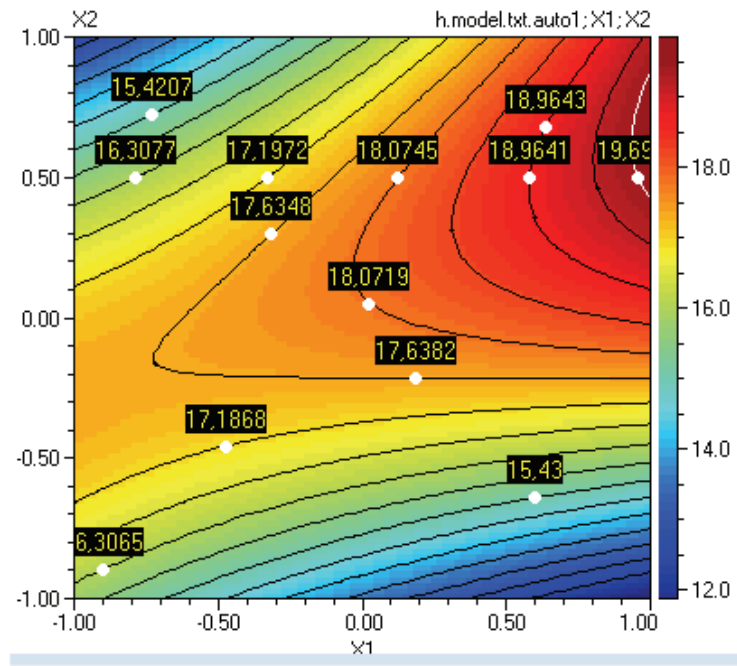

(a) $Y(h)=f\left(x_{1} ; x_{2}\right)$

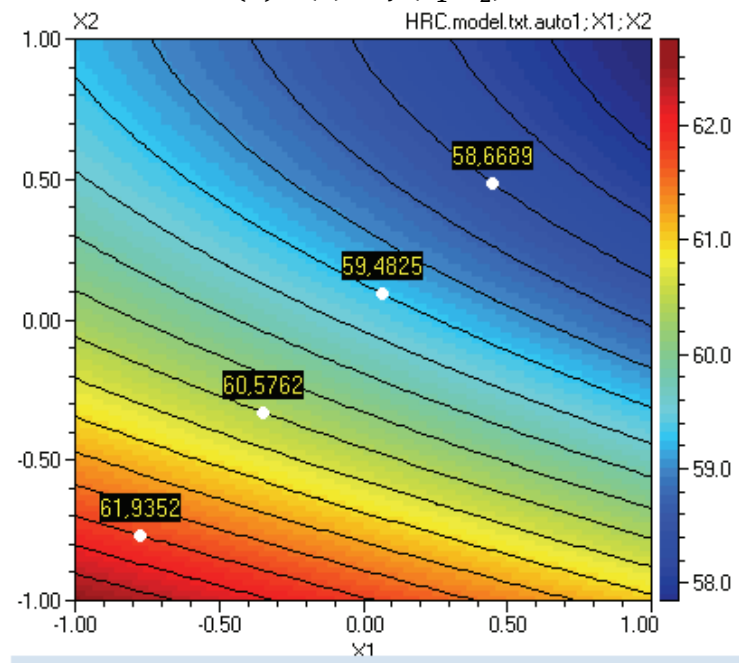

(c) $Y(H R C)=f\left(x_{1} ; x_{2}\right)$

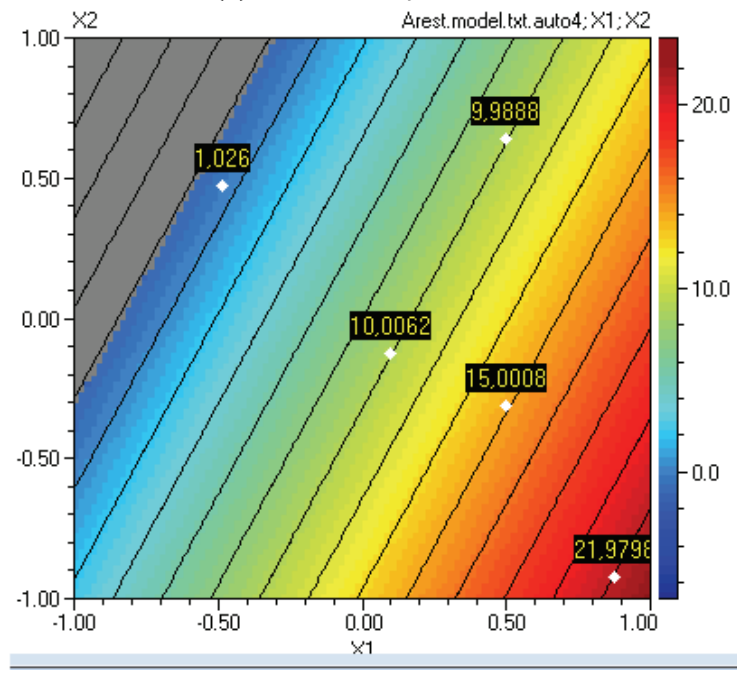

(e) $Y\left(A_{\text {rest }}\right)=f\left(x_{1} ; x_{2}\right)$

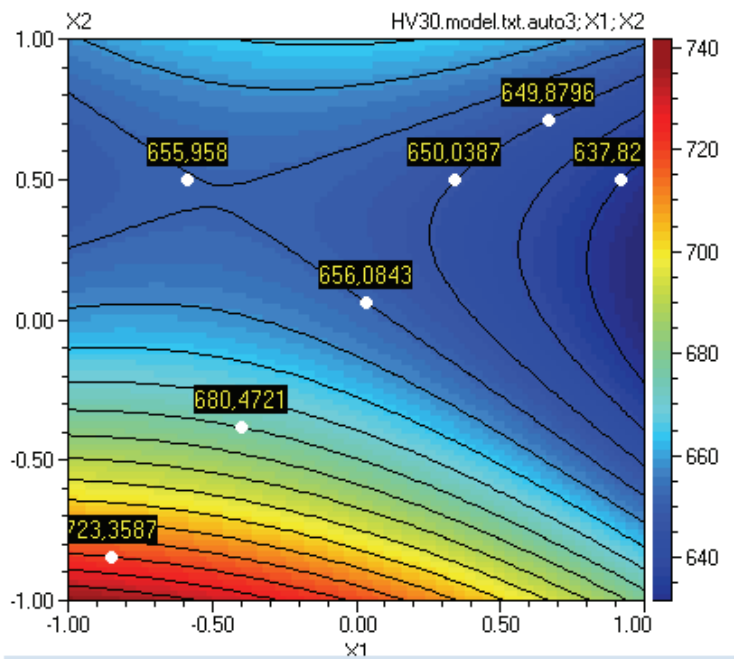

(b) $Y(H V 30)=f\left(x_{1} ; x_{2}\right)$

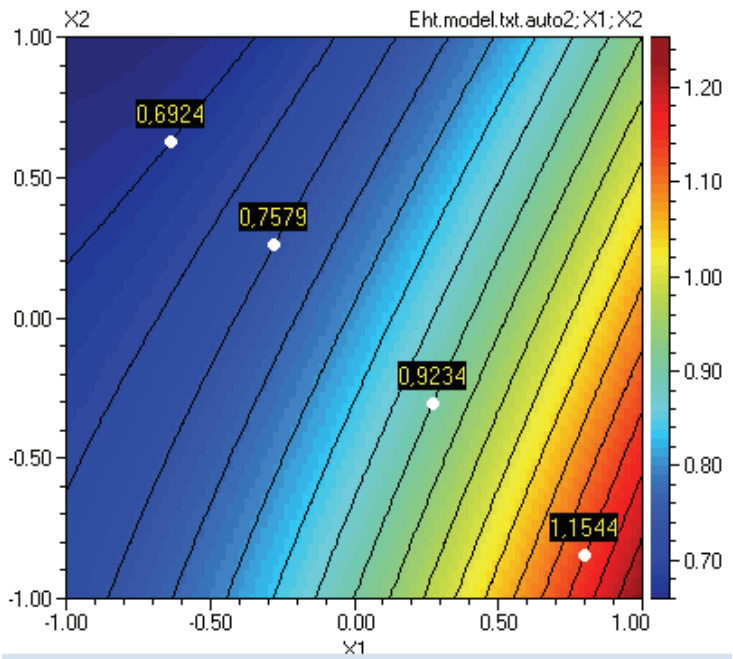

(d) $Y(C H D / E h t)=f\left(x_{1} ; x_{2}\right)$

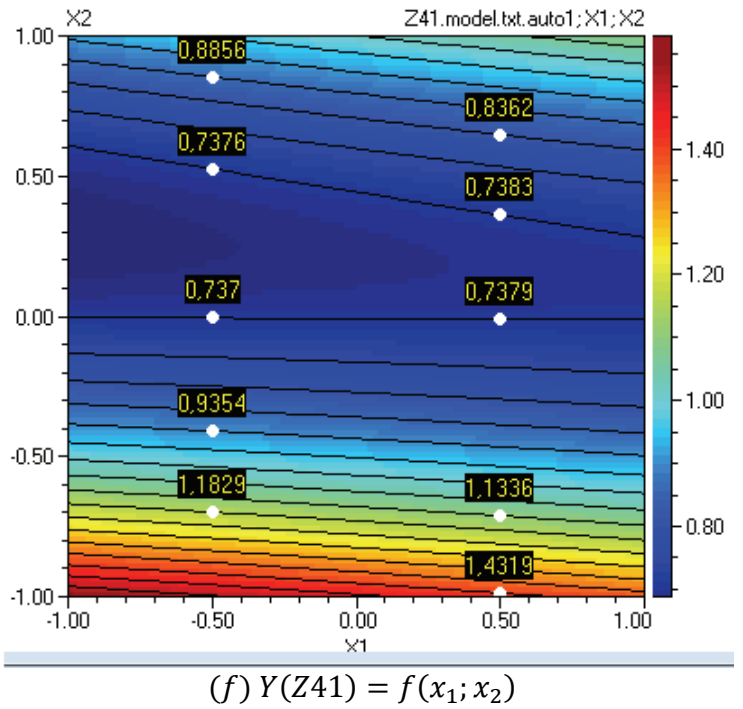

Fig. 1 Contours of constant values for DOE №1 models. 
Table 3 Statistical adequacy evaluation of DOE №1 regression models.

\begin{tabular}{llllll}
\hline Model & R-sq & Radj-sq & R-sq (pred) & F & $p$ \\
\hline$Y(h)=f\left(x_{1} ; x_{2}\right)$ & 0.95 & 0.90 & 0.62 & 19.1 & 0.007 \\
$Y(H V 30)=f\left(x_{1} ; x_{2}\right)$ & 0.97 & 0.92 & 0.60 & 18.9 & 0.0177 \\
$Y(H R C)=f\left(x_{1} ; x_{2}\right)$ & 0.95 & 0.92 & 0.84 & 30.6 & 0.0012 \\
$Y($ CHD $/$ Eht $)=f\left(x_{1} ; x_{2}\right)$ & 0.99 & 0.97 & 0.91 & 69.8 & 0.0006 \\
$Y\left(A_{\text {rest }}\right)=f\left(x_{1} ; x_{2}\right)$ & 0.81 & 0.75 & 0.56 & 12.8 & 0.0068 \\
$Y(Z 41)=f\left(x_{1} ; x_{2}\right)$ & 0.99 & 0.99 & 0.98 & 280.6 & 0.00001 \\
\hline
\end{tabular}

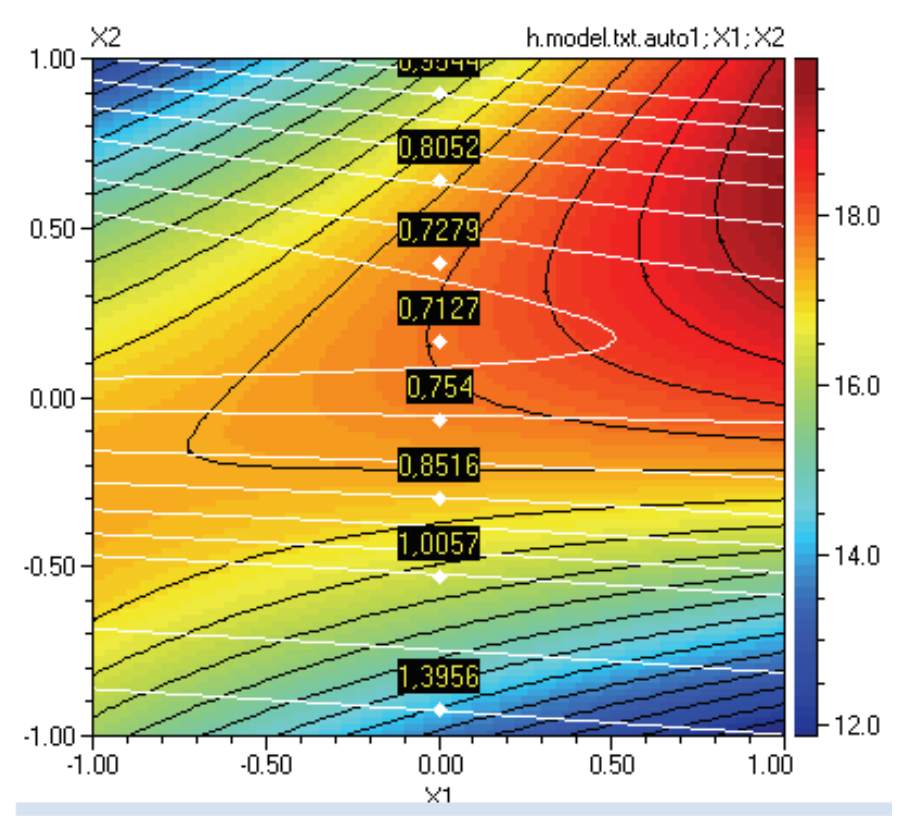

Fig. 2 Combined presentation of contours of the constant values (group control contour chart) for models $Y(h)=f\left(x_{1} ; x_{2}\right)$ and $\mathbf{Y}(\mathbf{Z 4 1})=\mathbf{f}\left(\mathbf{x}_{1} ; \mathbf{x}_{2}\right)$.

The statistical characteristics for the regression models lead to the conclusion that the models are adequate. However, the values of the ET instrument readings model stand out from the rest, which, on the one hand is an argument in favor of its introduction as a new quality indicator, and on the other hand, it reveals the intrinsic impossibility for the rest of the indicators to respond fully to the changes in the technological factors. It should not be forgotten that hardness measurements are localized in a thin surface layer, and the eddy current testing and the determination of the effective depth, $C H D$, work in a thicker layer, therefore they can be considered to have an integral character. It is not difficult to establish the positive correlation between indicators $C H D / E h t$ and $\% A_{\text {rest }}$, in Figs. $1 \mathrm{~d}$ and $1 \mathrm{e}$. It is interesting to notice that the high values of fatigue strength coincide with an area of low hardness values, measured by the HV30 method.

A point of interest, both for the technology and the control, would be the joint presentation of contours of the constant values for the fatigue strength models and the ET data $Y(h)=f\left(x_{1} ; x_{2}\right)$ and $Y(Z 41)=$ $f\left(x_{1} ; x_{2}\right)$ in Fig. 2.

Fig. 2 shows the expected ET results in the areas of minimal and maximal fatigue strength.

Table 4 presents the levels of the technological factors $T_{Q}$ and $T_{T}$ and the ET values for different working frequencies for $18 \mathrm{CrNiMo} 7-6$ steel, DOE №2 [10].

The regression models obtained are of the following type:

$$
\begin{aligned}
& Z_{1.6587}=b_{0}+b_{1} \cdot x_{1}+b_{2} \cdot x_{2}+ \\
& +b_{3} \cdot x_{1}{ }^{2}+b_{4} \cdot x_{2}{ }^{2}+b_{5} \cdot x_{1} \cdot x_{2},
\end{aligned}
$$


Table 4 ET characteristic value for different working frequencies 18CrNiMo7-6 steel samples [10].

\begin{tabular}{llllllllll}
\hline $\mathrm{T}_{\mathrm{Q}}$ & $\mathrm{T}_{\mathrm{T}}$ & $\mathrm{T}_{\mathrm{Q}}$ & $\mathrm{T}_{\mathrm{T}}$ & $\mathrm{Z}-1.6587-10$ & $\mathrm{Z}-1.6587-20$ & $\mathrm{Z}-1.6587-30$ & $\mathrm{Z}-1.6587-42$ & $\mathrm{Z}-1.6587-50$ & $\mathrm{Z}-1.6587-70$ \\
\hline 1 & -1 & 800 & 160 & 2.3 & 3.3 & 3.3 & 4 & 3.6 & 2.33 \\
1 & 0 & 800 & 200 & 3.05 & 4.25 & 4.5 & 5 & 4.5 & 3.1 \\
1 & 1 & 800 & 240 & 5.5 & 6.7 & 6.85 & 7.75 & 6.8 & 4.85 \\
0 & -1 & 840 & 160 & 2.05 & 3.2 & 3.45 & 4.25 & 3.75 & 2.5 \\
0 & 0 & 840 & 200 & 2.95 & 4.1 & 4.5 & 5.2 & 4.7 & 3.25 \\
0 & 1 & 840 & 240 & 5.25 & 6.6 & 6.85 & 7.65 & 6.8 & 4.9 \\
1 & -1 & 880 & 160 & 2.9 & 4.25 & 4.2 & 5 & 4.4 & 3.05 \\
1 & 0 & 880 & 200 & 2.55 & 3.85 & 4.25 & 5.55 & 4.65 & 3.25 \\
1 & 1 & 880 & 240 & 4.9 & 6.35 & 6.65 & 7.35 & 6.75 & 4.85 \\
\hline
\end{tabular}

Table 5 Statistical evaluation of the analytical models.

\begin{tabular}{|c|c|c|c|c|c|}
\hline & $\mathrm{F}$ & $p$ & R-sq & R-sq(adj) & R-sq(pred) \\
\hline Z-1.6587-10 & 67.90 & 0.00018 & 0.9760 & 0.9616 & 0.9295 \\
\hline Z-1.6587-20 & 65.78 & 0.00019 & 0.9752 & 0.9604 & 0.9083 \\
\hline Z-1.6587-30 & 117.75 & 0.00005 & 0.9860 & 0.9776 & 0.9375 \\
\hline Z-1.6587-42 & 231.45 & 0.00006 & 0.9957 & 0.9914 & 0.9700 \\
\hline Z-1.6587-50 & 197.73 & 0.00008 & 0.9949 & 0.9899 & 0.9621 \\
\hline Z-1.6587-70 & 189.66 & 0.00008 & 0.947 & 0.9895 & 0.9639 \\
\hline
\end{tabular}

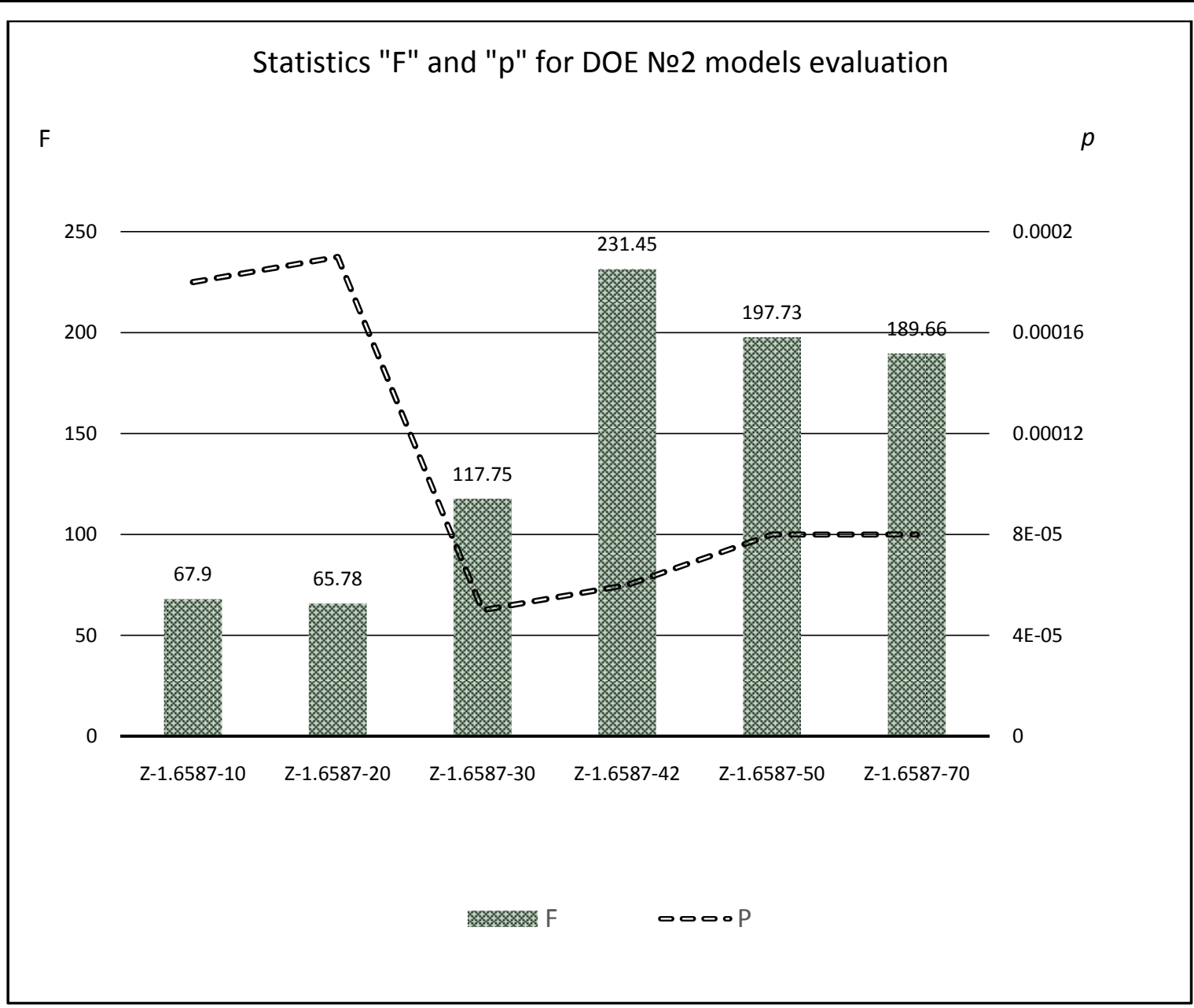

Fig. 3 F-statistic of regression models with varying frequency [10]. 
where $x_{1} \leftrightarrow T_{Q}$ is the quenching temperature, and $x_{2} \leftrightarrow T_{T}$ is the tempering temperature.

The statistical characteristics for the quality of DOE №2 models are given in Table 5 [10].

Fig. 3 is a graphical representation of the statistical estimate $F$ for the models with different, ascending, values for the frequency of the ET instrument

$$
F=\frac{R^{2} \cdot(N-k)}{\left(1-R^{2}\right) \cdot(k-1)^{2}}
$$

Where $R$ is the multiple correlation coefficient, $N$ is the number of experiments, $\kappa$ - the number of coefficients in the model [1]. The graph shows that the setting, designated as $Z 1.6587-42$, presents the highest value of the $F$ statistic, and the best statistical values for the rest.

\section{Results}

The analysis of the two designed experiments presented here suggests some important conclusions, which can be used to develop a methodology of eddy current testing of a specific technological object.

The ET method is sensitive to the changes in technological factors and can be added to the group of the traditional quality indicators.

The ET indications can be calibrated if they are jointly considered with another one, or more than one, quality indicators in the field of changes in the technological factors.

The ECT method can be optimized by determining an array of settings for different frequencies of the field current.

\section{Methodology for ET of Carburized Parts}

After a number of DOEs (designed experiments), the following steps have been established and confirmed for ET of carburized parts:

(1) A metallographic analysis is carried out, as well as hardness measurements, performance testing, and ET of the DOE samples. The parts subjected to the experiment are used for setting up the ET instrument.

(2) The effects of the technological factors are analyzed in order to optimize the thermochemical process.

(3) The effect of possible deviations in the levels of the technological factors is analyzed with reference to the quality indicators.

(4) The data are processed with a regression analysis, and contour charts are made, which show the variations in each quality indicator in relation with the changes in the technological factors.

(5) The obtained regression models are tested for adequacy. When the test results are inconclusive, opportunities for improving laboratory practices and test conditions are investigated, as well as other reasons. The aim is to find the optimal setting of the ET instrument, in relation to the working frequency, by using the samples involved in the designed experiment.

(6) The major influences are determined and the technological factors are classified according to their effect on the quality indicators.

(7) The major quality indicator is established.

(8) Group control contour charts are made (Fig. 2), on the basis of the variation of the leading quality indicator, which contain the contours of variation of the rest of the dependent quality indicators, one of which is invariably the ET evaluation.

(9) Two or more regression models are jointly analyzed in their informational and technological, as well as their control aspect, and levels are chosen for the formulation of well-founded technical requirements. Control tolerance limits are determined for non-destructive ET. This stage can be called "RQ+RZ", for short, as it combines regression analysis of quality indicators and a regression of the eddy current characteristic.

\section{Conclusions}

The reliability, effectiveness and efficiency of carburized parts ET depend on the relative consistency of the influencing technological factors in time. Eddy current testing does not dismiss the importance of any 
one of the other quality indicators, but it provides a quick instrument for finding technological solutions. The combination of all results with statistical methods of analysis and optimization make the technical control system high-powered and capable of improving.

\section{References}

[1] Vuchkov, I. N., and Boyadjieva, L. N. 2001. "Quality Improvement with Design of Experiments." Kluwer Academic Publishers, Dordrecht.

[2] Tsvetkov, D. N., et al. 1981. "Electromagnetic Defecto Metrix." Technology. Sofia 5-15: 222-40.

[3] Kalner, V. D. (ed.). 1984. "Quality Control in the Heat Treatment of Steel Parts and Semi-Finished Goods." In Reference Book. Machine building. (in Russian)

[4] Ivanov, J. 2010. "Eddy Current Structuroscopy, Technological Factors and Quality Indicators in Thermos-Chemical Treatment." In Proceedings of XXV National Conference with international participation "Defectoscopy'10". "NDT days 2010", Year XVII, Issue 5 (115), June 2010. Scientific news. Scientific Technical Union of Mechanical Engineering. ISSN 1310-3946: 594.

[5] Ivanov, J., et al. 2013. "Eddy Current Testing and Performance Prognosis of Carburized and Quenched Parts." XXVIII International Conference, "NDT days 2013", Year XXI, Issue 2 (139). June 2013. ISSN
1310-3946. Conference Proceedings, pp. 202-5.

[6] Hansen, J. 2004. "The Eddy Current Inspection Method." Part 1-4. Insight .Vol. 46, No. 5.

[7] Baumgartner, H. 2012 "Eddy Current Test." Handbook of Induction Heating.

[8] Bernard, M., Reimche, W., and Bach, Fr.-W. 2007. "Zerstörungsfreie Bestimmung der Randzoneneigenschaften hochbeanspruchter Maschinenbauteile."Institut für Werkstoffkunde. Leibniz Universität Hannover. DGZfP - Jahrestagung 2007-Poster 34.

[9] Schiebold, K., and Knöll, T. 2006."Fehlerprüfung mit Wirbelstrom.” Castell-Verlag GmbH. Wuppertal. 2006. in Zusammenarbeit mit Karl Deutsch, DB, DGZfP.

[10] Ivanov, J. 2014. "Eddy Current Study of Steels $30 \mathrm{CrNiMo} 8$ and $18 \mathrm{CrNiMo} 7-6$. Procedures for Eddy Current Testing and Determination of Working Frequency." "NDT days 2014".Year XXII, Issue 1 (150): 335-8. June2014. ISSN 1310-3946.

[11] DIN EN 10084 Einsatzstähle-TechnischeLieferbedingungen.

[12] DIN EN ISO 6507 MetallischeWerkstoffeHärteprüfungnachVickers.

[13] DIN EN ISO 6508 MetallischeWerkstoffeHärteprüfungnach Rockwell.

[14] DIN EN ISO 2639 Stahl: Bestimmung und Prüfung der Einsatzhärtungstiefe.

[15] EN 12084 General Principles of Eddy Current Testing.

[16] Qstat Lab: Software for Statistical Process Control and Robust Engineering. 